\title{
Impacts of Uranium Utilization Improvements on Light Water Reactor Radionuclide Releases
}

\author{
R. L. Aaberg
}

August 1981

Prepared for the Environmental and Safety Engineering Division U.S. Department of Energy under Contract DE-AC06-76RLO 1830

Pacific Northwest Laboratory Operated for the U.S. Department of Energy by Battelle Memorial Institute 


\title{
NOTICE
}

This report was prepared as an account of work sponsored by the United States Government. Neither the United States nor the Department of Energy, nor any of their employees, nor any of their contractors, subcontractors, or their employees, makes any warranty, express or implied, or assumes any legal liability or responsibility for the accuracy. completeness or usefulness of any information, apparatus, product or process disclosed, or represents that its use would not infringe privately owned rights.

The views, opinions and conclusions contained in this report are those of the contractor and do not necessarily represent those of the United States Government or the United States Department of Energy.

\author{
PACIFIC NORTHWEST LABORATORY \\ operated by \\ BATTELLE \\ for the \\ UNITED STATES DEPARTMENT OF ENERGY \\ Under Contract DE-AC06-76RLO 1830
}

\author{
Printed in the United States of America \\ Available from \\ National Technical Information Service. \\ United States Department of Commerce \\ 5285 Port Royal Road \\ Springfield, Virginia 22151
}

Price: Printed Copy \$ $\because$ Microfiche $\$ 3.00$

$\begin{array}{cr}\text { *Pages } & \begin{array}{c}\text { NTIS } \\ \text { Selling Price }\end{array} \\ 001-025 & \$ 4.00 \\ 026-050 & \$ 4.50 \\ 051-075 & \$ 5.25 \\ 076-100 & \$ 6.00 \\ 101-125 & \$ 6.50 \\ 126-150 & \$ 7.25 \\ 151-175 & \$ 8.00 \\ 176-200 & \$ 9.00 \\ 201-225 & \$ 9.25 \\ 226-250 & \$ 9.50 \\ 251-275 & \$ 10.75 \\ 276-300 & \$ 11.00\end{array}$




\section{3}

PNL -3584

IMPACTS OF URANIUM UTILIZATION

IMPROVEMENTS ON LIGHT WATER

REACTOR RADIONUCLIDE RELEASES

R. L. Aaberg

August 1981

Prepared for

the Environmental and Safety Engineering Division U.S. Department of Energy

under Contract DE-AC06-76RL0 1830

Pacific Northwest Laboratory

Richland, Washington 99352 
$d$

•

. 


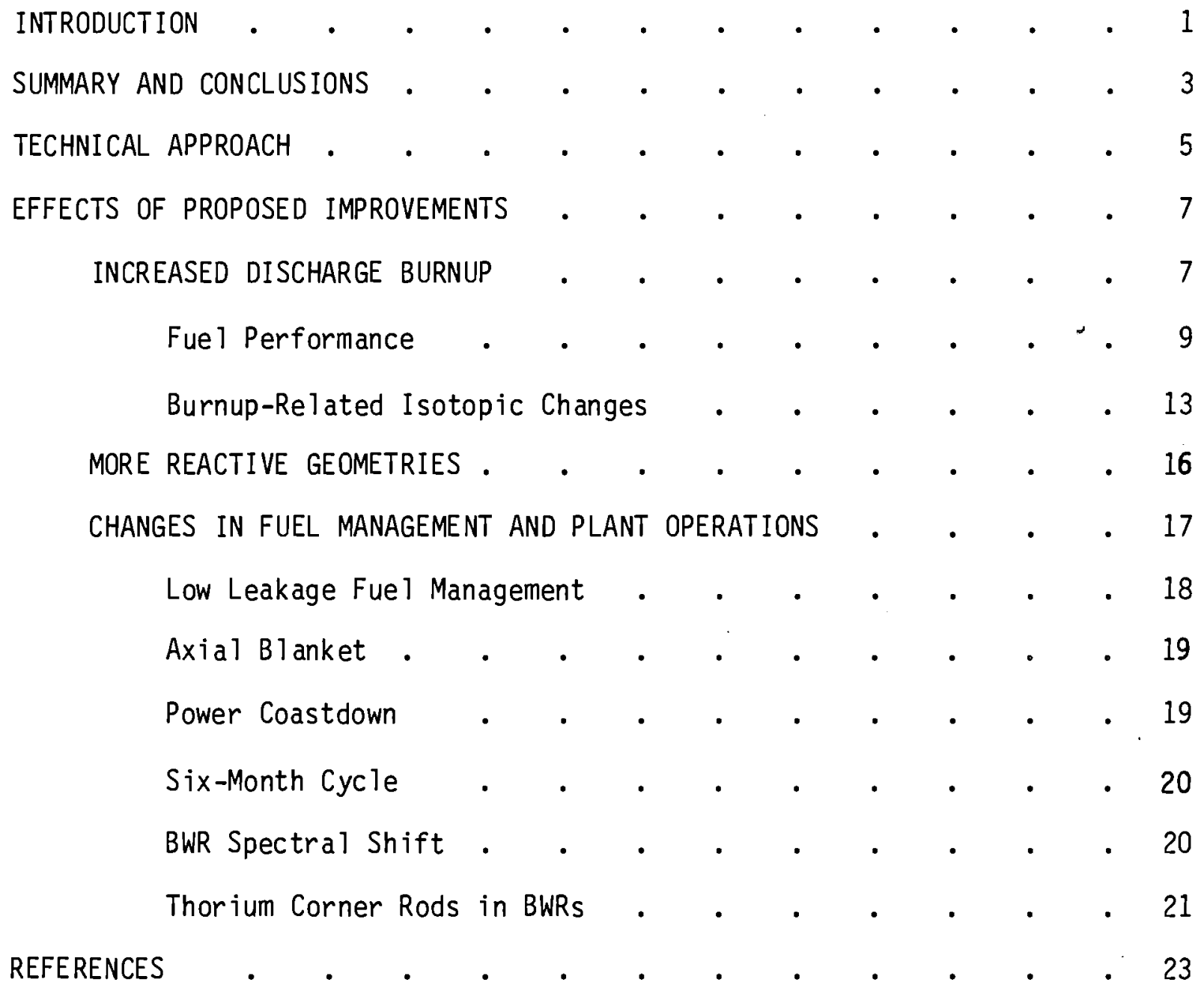




\section{FIGURES}

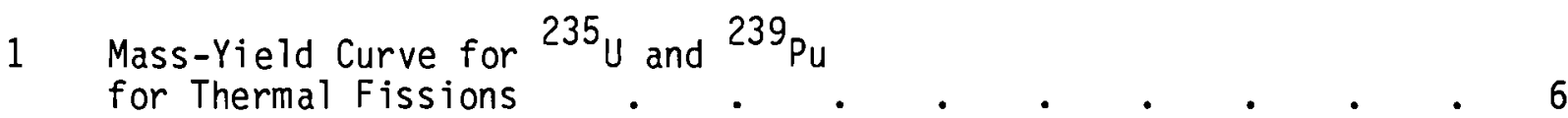

2 Uranium Requirement Versus Discharge Exposure

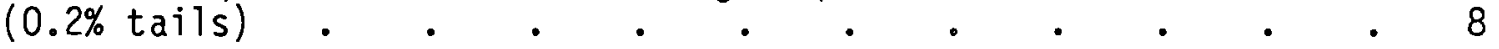

3 Fission Product and Heavy Element Inventories From 30 to $50 \mathrm{GWd} / \mathrm{MT}$ Fue 1 Activity at Discharge,

0.1 Year, and 1.0 Year . . . . . . . . . . 12

4 Activity at Discharge of Volatile Fission Products for 30, 40, and $50 \mathrm{MWd} / \mathrm{MT}$ Burnup Fuel . . . . . 15

\section{TABLES}

1 The Estimated Effect on LWR Radionuclide Releases of Methods of Increasing Uranium Utilization. . . . . 3

2 Present $17 \times 17$ Versus Optimized Westinghouse Assemblies 


\section{INTRODUCTION}

Current U.S. policy emphasizes increased uranium efficiency in light water reactors (LWRs). Several methods have been proposed to improve LWR uranium utilization, and each of the potentially feasible plant modifications needs to be examined to determine the potential impact on routine radionuclide releases.

Previous environmental control technology tasks (Heeb et al. 1980; Schneider and Kabele 1979) have characterized radionuclide releases based on current LWR plant design and operating practices. This report discusses potential changes to these releases as a result of uranium-saving plant modifications and altered operating practices. Only releases to the environment from routine operation are considered; releases resulting from abnormal conditions outside the technical specifications covering plant operation are not considered.

Routine releases are affected by the size of the radionuclide inventory and the various pathways that convey the material to the environment. The measures that improve plant uranium utilization have a potential impact on both the inventory and the mechanism of release. Increases in the radionuclide inventory can be calculated by well-proven reactor burnup methods. However, when dealing with the effect on the fuel failure rate, the conclusions are necessarily more uncertain because the technology is in an emerging state of development. 
In general, it appears that implementation of the methods examined will not result in drastic increases in radionuclide releases to the environment. The results are sumarized in Table 1 . The most predictable increase will come from the proposed increases in discharge exposure. This will increase the radionuclide inventory, which is the source term for all radioactive releases. Judgments as to the effect on the fuel rod failure rate due to higher burnup are much more uncertain. It is clear that a decrease in the failure rate is

TABLE 1. The Estimated Effect on LWR Radionuclide Releases of Methods of Increasing Uranium Utilization

Method of Increasing Uranium Utilization Release Effect ${ }^{(a)}$

Increased Burnup:

Higher Radionuclide Inventory +3

Higher Fuel Failure Rate from:

Pellet-Clad Interaction +2

Fuel Rod Internal Pressure +1

External Clad Corrosion +1

Fuel Assembly Dimensional Changes 0

More Reactive Geometries $\quad 0$

Fuel Management and Plant Operation:

Low Leakage Fue 1 Management 0

Axial Blanket 0

Power Coastdown 0

6-Month Cycles 0

BWR Spectral Shift +1

Thorium Corner Rods in BWRs +1

(a) +3 Certain increase

+2 Probable increase

+1 Possible increase

0 Negligible effect 
not expected and therefore some increase is probable. Increases will result from pellet-cladding interactions and possibly from external clad corrosion and fue 1 rod pressurization. Fue 1 assembly dimensional changes are much less likely to cause problems.

Modifications based on altered fuel management or plant operation are expected to have a negligible effect on release rates. The use of thorium corner rods and BWR spectral shift were both found to make small changes to the radionuclide inventory. 
TECHNICAL APPROACH

The information in this document was developed from literature review and independent isotopic calculations. Major review topics included fuel failure mechanisms, pellet-clad interaction (PCI), coolant activity, and Zircaloy corrosion. High burnup fuel compositions were determined using a cell burnup code, which is an extensive revision of LEOPARD (Barry 1963). Initial fissile loadings were determined by matching end-of-life $K$-infinity to the $K$ value of a $3 \%$ enriched, 30 MWd/MT burnup. Spectral information from LEOPARD was used in ORIGEN (Bel1 1973) to generate isotopic compositions.

Changes in LWR fuel and operation, such as high burnup fuels and thorium and spectral shift in BWRs can change the proportion of fissions by ${ }^{235} \mathrm{U}$, ${ }^{239} \mathrm{Pu}$, and ${ }^{233} \mathrm{U}$ because each fissile isotope yields a different distribution of fission products. The distribution in mass of the fission fragments, percentage yield per fission versus mass number, is shown in Figure 1 for ${ }^{235} \mathrm{U}$ and ${ }^{239} \mathrm{Pu}$. In general, the two fragments formed have unequal masses; the most probable heavy mass is about 139 and the most probable light mass is about 95 atomic mass units. The yields vary from about $10^{-4}$ percent on the edges of the distribution to about 6 percent at the two peaks of the distribution. The mass of the heavy peak remains fixed, with only the light peak shifting to reflect the changing masses of the fissioning species.

Possible changes in the fission product distribution were investigated with respect to a possible effect on the source term for LWR effluents. 


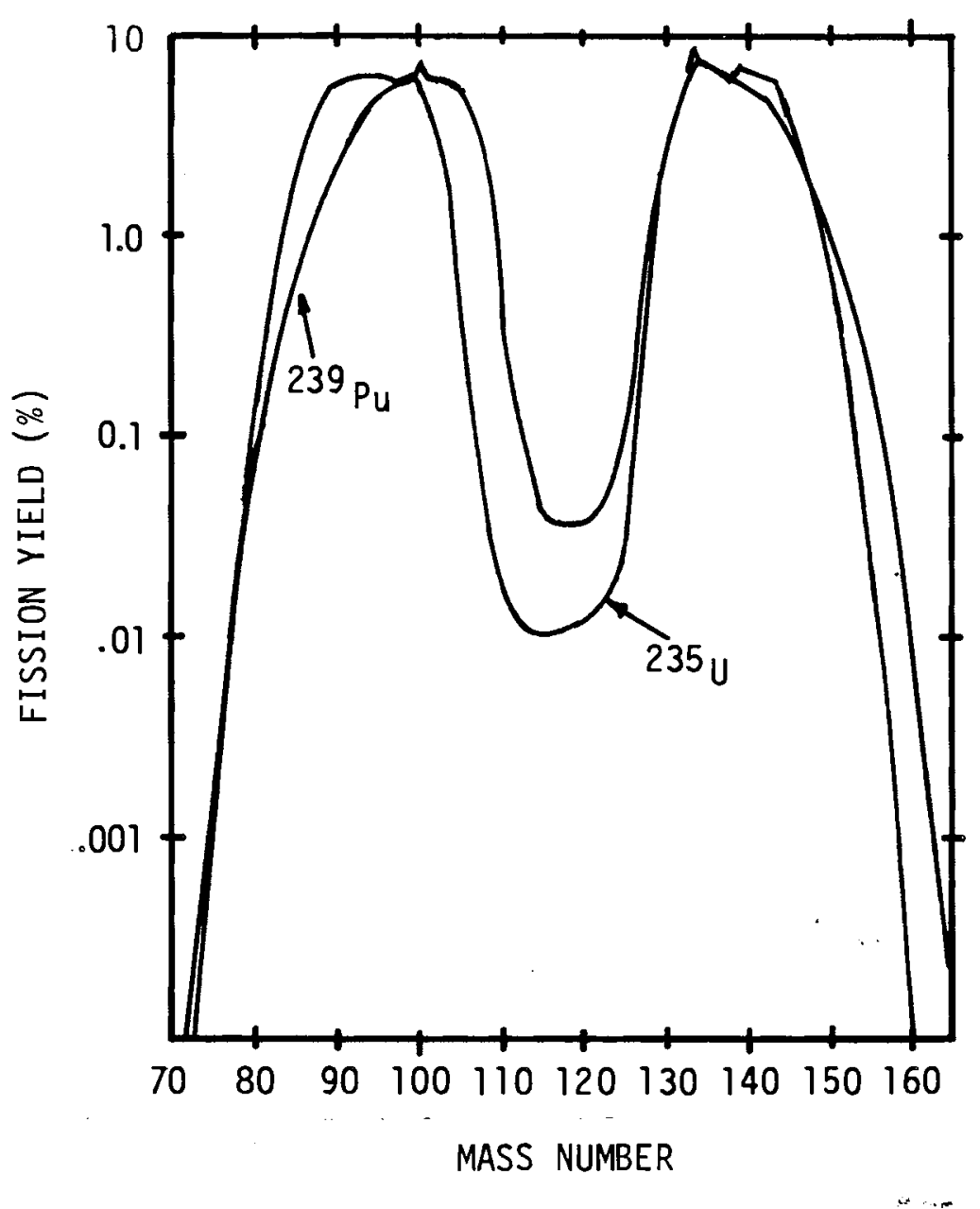

FIGURE 1. Mass-Yield Curve for ${ }^{235} \mathrm{U}$ and ${ }^{239} \mathrm{Pu}$ for Thermal Fissions

Source: Keepin 1965, pp. 22,23. 


\section{EFFECTS OF PROPOSED IMPROVEMENTS}

INCREASED DISCHARGE BURNUP

Increased fuel discharge exposure and, thus, increasing the number of fuel batches in the core appears to be the most acceptable method for increasing uranium utilization because it involves minimal change to reactor structure or operating procedures. Proposed improvements have the potential of reducing uranium requirements by 5 to 15\% (NASAP 1980).

Current ly, PWR fuel average goal burnup is 30 to 34 GWd/MT. Proposed changes include an increase in exposure to 45 to $50 \mathrm{GWd} / \mathrm{MT}$. The average goa 1 discharge exposure of current BWR fue 1 is about $28 \mathrm{GWd} / \mathrm{MT}$. Increased burnup to 40 to $45 \mathrm{GWd} / \mathrm{MT}$ is being considered.

Figure 2 shows the relationship between uranium requirements, burnup, and refueling interval. Increasing burnup and number of batches (decreasing refueling intervals) improve fuel utilization. By increasing burnup from 30 to 50 GWd/MT and increasing the number of batches from 3 to 5 , an $18 \%$ improvement in fuel utilization is achieved. (a) The primary increase in fuel utilization is from the increase in the number of batches. Only about $5 \%$ of the increase is from higher burnup (Decher and Shapiro 1979, p. 16).

Longer cycles have a negative effect on $\mathrm{U}_{3} \mathrm{O}_{8}$ utilization. At current burnup design limits, an 18 -month PWR cycle requires 7 to $10 \%$ more $\mathrm{U}_{3} \mathrm{O}_{8}$. At higher burnup, the $\mathrm{U}_{3} \mathrm{O}_{8}$ penalty becomes smaller. BWRs show a similar trend (NASAP 1980, Vol. 9, p. 19). For equal uranium efficiency, an 18-month cycle requires a higher burnup than a 12 -month cycle. To break even with a 12 -month PWR cycle at $30.4 \mathrm{GWd} / \mathrm{MT}$, an 18-month cycle requires a burnup of 39 GWd/MT (NASAP 1980, p. 26). For a BWR, a burnup of 37 GWd/MT is equivalent in uranium efficiency to a 28 GWd/MT 12 -month cycle (NASAP 1980, p. 35).

Although increased cycle length decreases uranium utilization, it is attractive to utilities for maintaining a high capacity factor and for lowering personnel exposure. The use of high burnup fuel will effect some operating

(a) $18 \%$ increase in uranium utilization (MWd/MT $U_{3} 0_{8}$ ) equals a $15 \%$ reduction in uranium requirement ( $\left.M T \mathrm{U}_{3} \mathrm{O}_{8} / \mathrm{MWd}\right)$. 


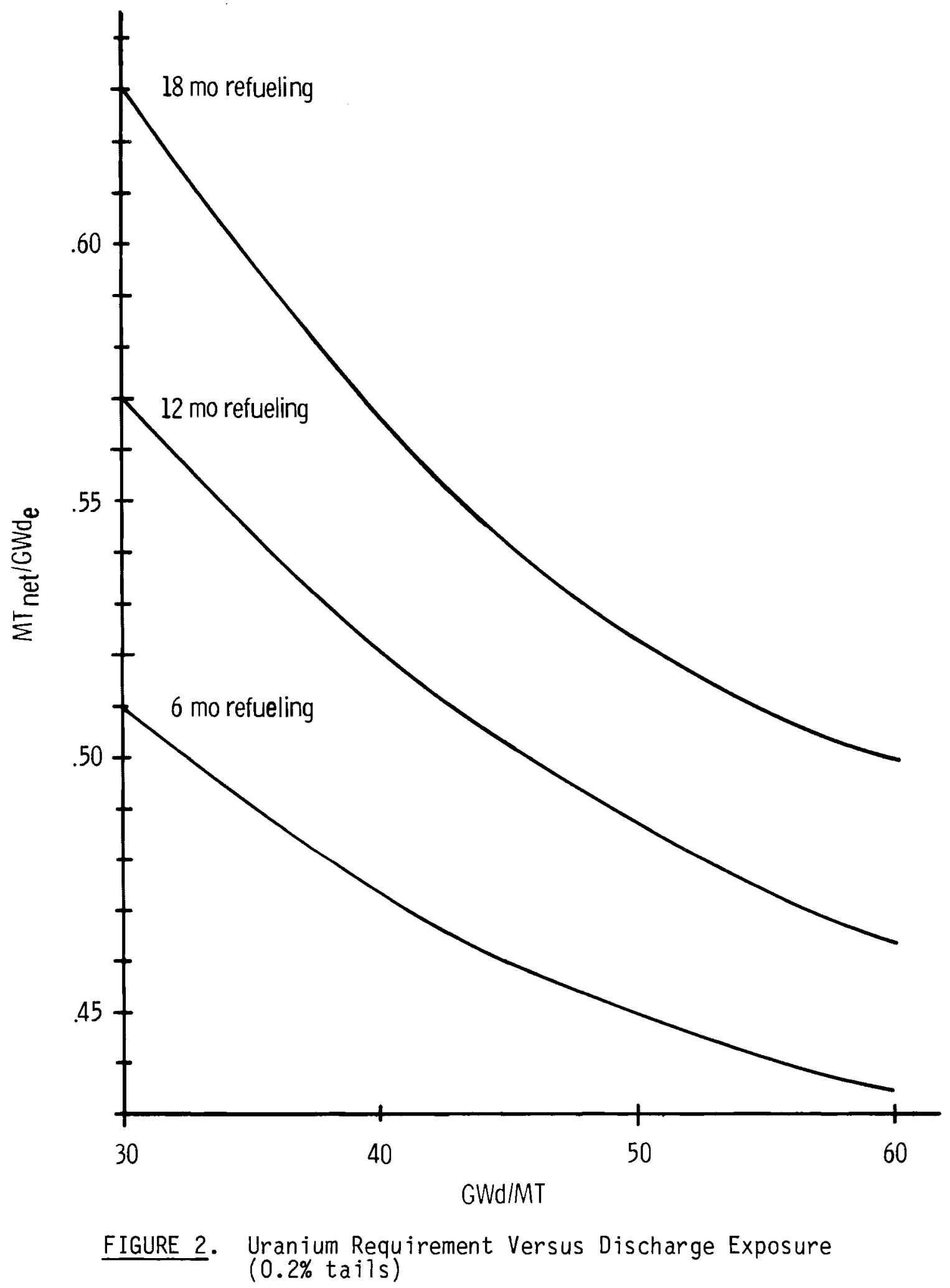


variables. An evaluation of reactor safety parameters for high burnup fuel with 5-batch fuel management has been made by Combustion Engineering (Decher and Shapiro 1979, p. 40). No fundamental problems are expected with this design. Safety analys is of a 5-batch design must be updated to assure that the results are acceptable to the NRC. These problems are minor compared with more severe nonbackfittable LWR modifications. Therefore, higher burnups and smaller size batches may become standard industry practice.

\section{Fuel Performance}

The impact of increased burnup on fuel performance is important for environmental considerations. Increased fuel failures have the potential for increasing radiation exposure to plant personnel and the public, compounding problems of storage and disposal, increasing the cost of power generation, and increasing the complexity of plant radioactive waste disposal systems.

Additional fuel rod failures would cause more volatile radioactive fission products to escape into the reactor coolant. Current design limit is $1 \%$ failed fuel. (This is higher than PWR experience.) An increase in fuel failures would affect the release rate of the volatile fission products.

In the past, internal fuel element failures have been caused by internal contamination (hydriding), manufacturing defects, mechanical damage, fuel pellet-cladding interactions, accelerated corrosion, fuel rod bowing, cladding collapse (densification of fuel), and other miscellaneous causes (Bobe 1976, p. 26). More recent production fuels have improvements in design, manufacturing, and quality assurance.

Current concerns about fuel performance at increased burnup include:

- pellet-clad interaction (PCI)

- fuel rod internal pressure

- external clad corrosion

- fuel assembly dimensional changes.

\section{Pellet-Clad Interaction}

Pellet-clad interaction is a failure mechanism that involves localized mechanical loading of the cladding at pellet interfaces and cracks. The strain on the clad is primarily caused by differential thermal expansion and fuel 
swelling. The main PCI problems have been with BWR and CANDU fuel rods, although PWR failures have also occurred. The occurrence of PCI is dependent on burnup, local power level, rate of power change, design characteristics, and manufacturing variables. A rapid rate of power increase at a sufficiently high burnup can lead to clad failures (Ranjan and Smith 1975, p. 2). A slow ascent to full power to precondition the fuel was proposed by General Electric (Bobe 1976, p. 10).

The greatest potential for failure is later in life when the cladding has reduced ductility (Bobe 1976, p. 10). Fuel becomes more susceptible to PCI failure with burnup increase for two major reasons:

1. High clad stresses occur with closure of fuel-clad gap resulting from creepdown and pellet swelling and relocation.

2. Increased corrosive fission products (iodine and cesium) that contribute to stress corrosion cracking (SCC).

Further tests will have to be done to determine if PCI-type failures become worse for extended burnup fuels. However, the propensity for PCI may not be significantly greater than for standard burnup fuels (Decher and Shapiro 1979, p. 53). The main reason is that peak cladding stresses are not expected to be burnup dependent after firm contact of clad and fuel, or after two cycles of irradiation. Corrosive fission products sufficient to produce SCC are likely to be available after two cycles of irradiation and increases in corrosive species concentrations with burnup should not further increase the probability of SCC. However, the probability of fuel failure due to PCI may be greater because of the longer period of time that the fuel is susceptible to PCI-type failures. DOE currently is investigating the PCI phenomenon and recognizes the importance of reduced cladding failures to the acceptability of increased fuel exposure to the utilities.

\section{Fuel Rod Internal Pressure}

The release of fission gas at high burnup is believed to be the most significant factor that could potentially limit discharge burnup of fuel in LWRs (Decher and Shapiro 1979, p. 57). PWR fuel rods are pressurized with helium to improve gap conductance and resistance to cladding creepdown. Fission gas, which is released as the fuel is irradiated, increases rod pressure 
and may exceed design limits for end of life at high burnup. Also, release of fission products xenon and krypton can reduce gap conductance, thus increasing fue 1 temperature and releasing additional fission gas.

There are a number of design options potentially available to reduce internal gas pressure. These include increasing the length of the fission gas plenum by lengthening or shortening the active length of the fuel rod, or using annular pellets.

Overpressurization is of concern because the cladding would expand away from the fuel into the coolant channel, impeding coolant flow and decreasing gap conductance. This can be avoided by keeping internal rod pressure under primary system pressure (2200 psia for PWRs).

Current "cold" fue 1 pressures are usually 250 to 500 psi for PWRs at discharge and 30 psi for BWRs.

Higher burnup implies a greater inventory of fission products. Fission gas is burnup dependent but the dependence has been shown to decrease after 10 MWd/MT (Bradley et al. 1979). At equivalent failure rates at high internal fission gas pressure, more krypton, iodine, cesium, and xenon should escape from the fuel pins.

The estimates of increased fission gas (shown in Figure 3 ) are based on isotopic calculations computed with ORIGEN (Bell 1973). Fission gas effluent releases also depend upon fission gas released to the fuel-clad gap and fuel failure rates. Data for gas release to the gap does not exist above 20 GWd/MT burnup.

\section{External Clad Corrosion}

Research on external clad corrosion failures from increased exposure and residence time is being sponsored by EPRI. In the past, primarily BWRs have suffered fuel failures due to corrosion deposits. These have been attributed to excessive amounts of feedwater system corrosion products in plants with cupro-nickel or monel feedwater heaters (Bobe 1976, p. 11). Current LWRs have not experienced excessive corrosion on the outside surface of fuel rods.

Irradiation enhancement of corrosion rate has not occurred under normal operating conditions in current Westinghouse PWRs (Solomon 1978). 


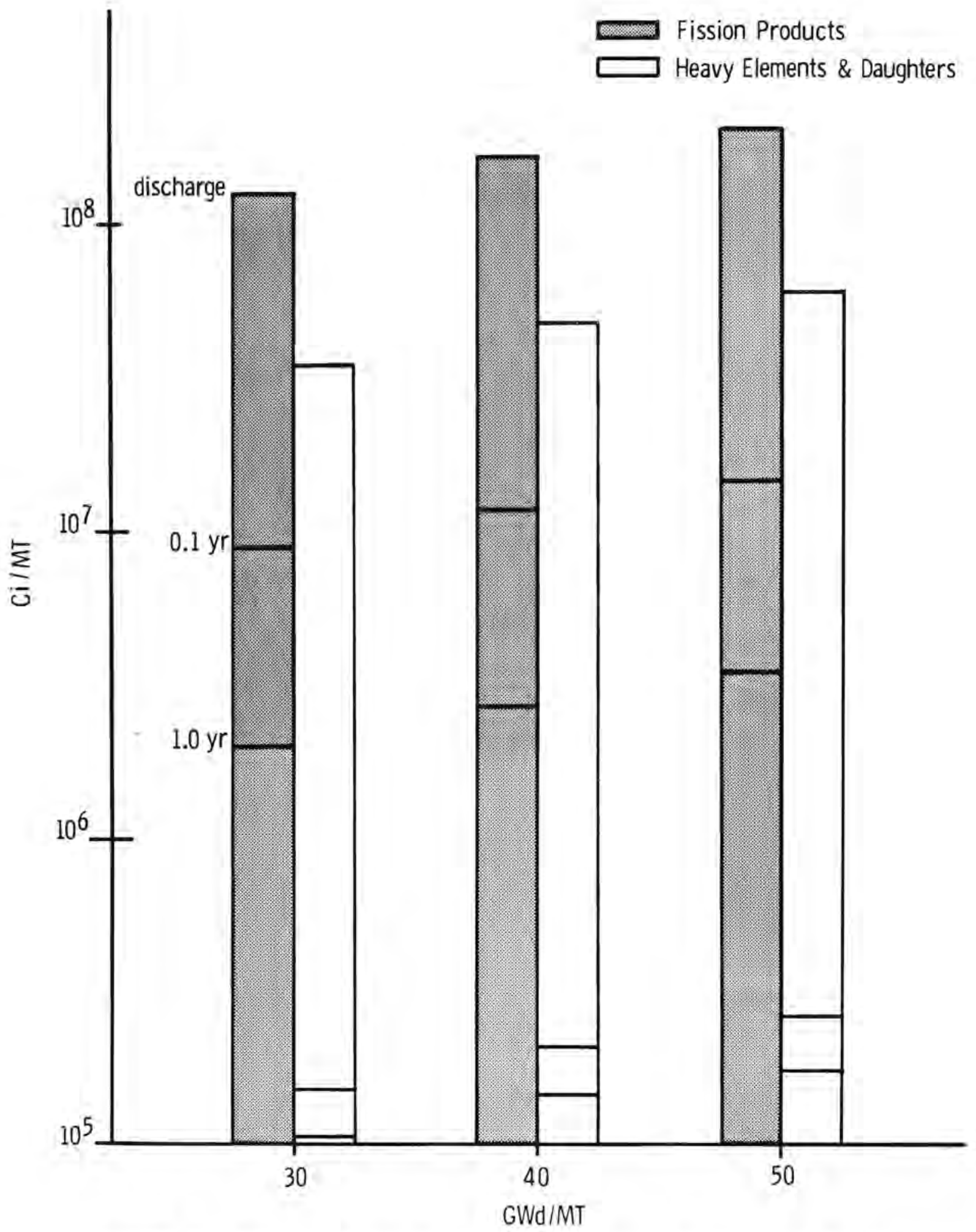

FIGURE 3. Fission Product and Heavy Element inventories From 30 to $50 \mathrm{GWd} / \mathrm{MT}$ Fuel Activity at Discharge, 0.1 Year, and 1.0 Year 
Crud deposit on fuel rods is the result of deposition and erosion of particles and dissolution and precipitation of soluble species (Solomon 1978). This action results in a steady-state crud buildup. "Apparent residence time" of crud is a relative measure of crud mobility (Roesmer and Rootham 1978). They are derived from the ratio of radioactivity to chemical concentration of the parent species. Measured apparent residence times for different chemical species from two PWR cores averaged 11 to 87 days (Roesmer and Rootham 1978). Since these residence times are much shorter than actual residence time of the fuel, the radionuclide content of the crud apparently reaches steady state. Therefore, the crud composition should not change with longer irradiation periods. Increased insulation from corrosion and crud deposition may raise oxideclad interface temperatures sufficiently to accelerate corrosion. However, presently available data suggests that Zircaloy corrosion may be acceptable for the 5-yr residence times being considered for high-burnup fuel (Decher and Shapiro 1979, p. 57). The effects of increased residence times and irradiation damage on corrosion rates, crud buildup, and clad temperatures will have to be addressed relative to safety and licensing concerns, however, there appears to be no current evidence to believe that radionuclide releases will be drastically increased by an increased number of external corrosion failures at higher burnup.

\section{Fuel Assembly Dimensional Changes}

Irradiation can cause dimensional changes in the components of the fuel assembly. These include axial growth of the fuel rods, poison rods, and control-rod guide tubes, fuel and poison rod bowing, fuel assembly bowing and retention grid relaxation. Fuel rod and assembly design changes should accommodate these dimensional changes (Decher and Shapiro 1979, p. 56). These changes are not expected to affect any radionuclide releases.

\section{Burnup-Related Isotopic Changes}

Higher burnup discharged fuel could lead to greater releases of radionuclides either from increased inventory or failure rate. The radioactive effluent releases in the ECT analysis document (Schneider and Kable 1979) were based on burnups of 33 GWd/MT for PWRs and 27 GWd/MT for BWRs. Current proposals for increased burnup are in the 40 to $50 \mathrm{GWd} / \mathrm{MT}$ range. The effects of 
increased inventories of fission products and heavy elements are shown in Figure 3. The activities are shown for each burnup and the activities for $0.1 \mathrm{yr}$ and $1 \mathrm{yr}$ after discharge are indicated.

The major radioactive effluents of concern from nuclear power plants are volatile fission products. Figure 4 shows the activity at discharge of volatile fission products for PWRs. The discharge activity is approximately proportional to burnup. The activity for 40 and 50 GWd/MT burnups are approximately one-third and two-thirds higher than for 30 GWd/MT burnup. This indicates that with no other changes to the system and no additional fuel defects, the release rate of these fission products will increase proportionally. Higher burnup fuels having a larger fraction of fission gas released into the cladding gap may further increase the effluent gas release rate.

Most of the effluent tritium from PWRs is produced from activation of boron shim in the coolant (Trevorrow et a1. 1974, p. 21). However, increased burnup accompanied by necessarily higher enrichment increases the need for burnable poison in the reactor and for more extensive use of control rods. In initial cycles, PWRs use borosilicate glass burnable poison rods in which the tritium produced by boron activation is contained in the structure of the glass. Higher burnup designs with burnable poison rods in every batch would not affect effluent tritium for this reason.

The use of boron for cold shutdown of BWRs has been considered. Coolant cleanup would be done before significant power generation took place. However, some questions must be answered about the use of boron for cold shutdown such as time required for removal, problems with transients, and boron plateout. This operation would add another water cleanup system and an extra waste stream. Corrosion of turbine blades and materials problems from the use of boric acid are other causes for concern.

The production of tritium from residual boron is another potential effect. Assuming the boron residual would be about $1 \%$ of the amount of boron used in PWRs, about 5 to $10 \mathrm{C}$ igWeYr should appear in waste streams. This is 2 to $5 \%$ of the amount of tritium appearing in waste streams from fission and deuterium activation, based on $1 \%$ failed fuel (Trevorrow et al. 1974, p. 7). 


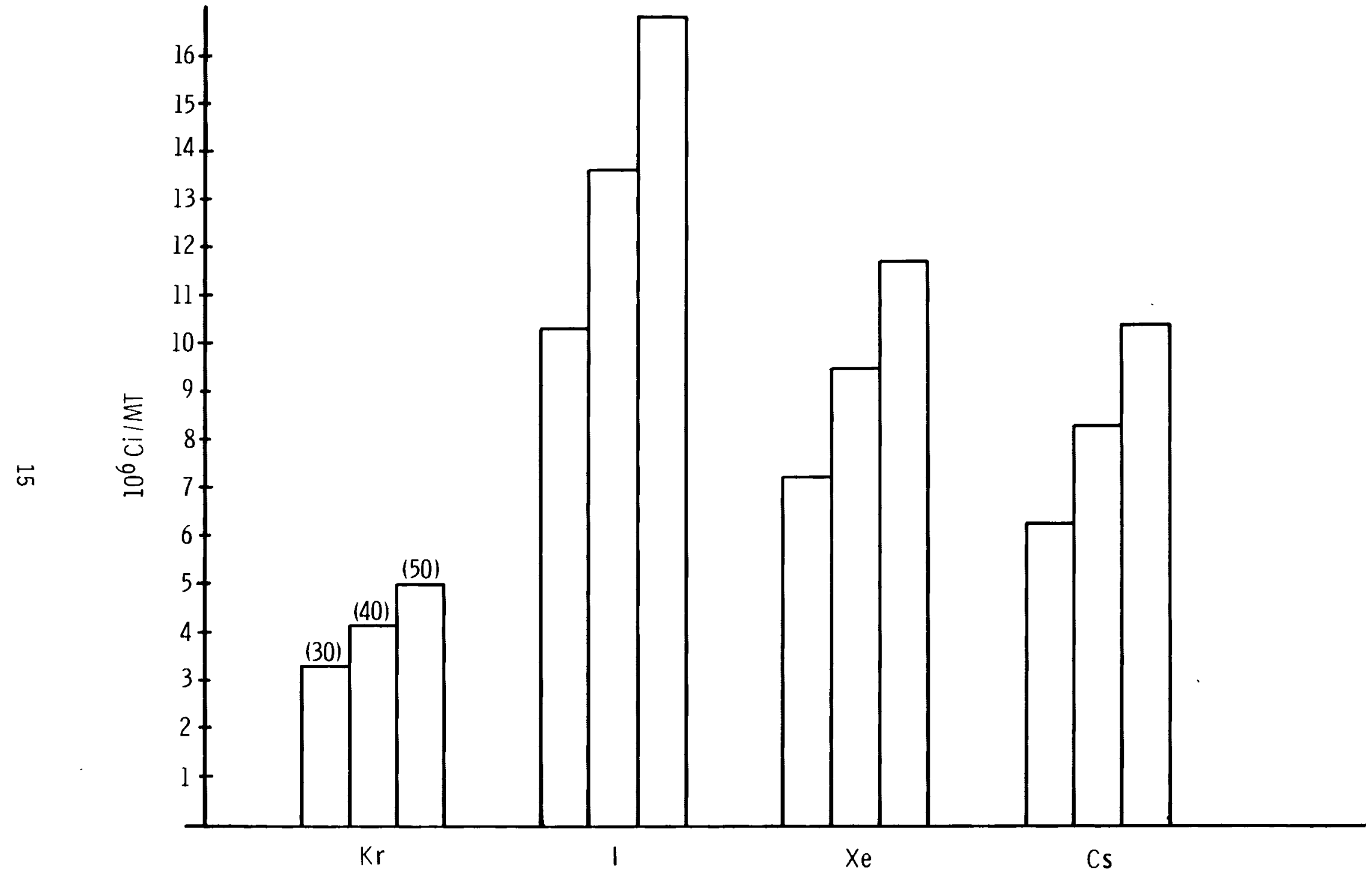

FIGURE 4. Activity at Discharge of Volatile Fission Products for 30, 40, and 50 MWd/MT Burnup Fuel 


\section{MORE REACTIVE GEOMETRIES}

Increasing the reactivity of lattice geometries by increasing the hydrogen to uranium (H/U) ratio will improve uranium utilization. Changes in the $H / U$ ratio can be made with changes in fuel rod pitch, pellet and clad diameter, and effective fuel density. The reduction of uranium requirements would be from 2 to $3 \%$ (NASAP 1980, p. 23 ).

Increases in the $H / U$ ratio in PWRs are limited by the positive increase in the moderator temperature coefficient (MTC). The MTC increase is partially offset by a more negative MTC for a 5-batch rather than 3-batch fuel management scheme.

A study by Combustion Engineering (Decher and Shapiro 1979) has estimated savings for the following methods of achieving more reactive lattice geometries:

- fuel density reduction (1.1\%)

- increased pitch (2.1\%)

- reduced fuel pellet diameter (1.5\%)

- reduced clad thickness (4.5\%).

An example of a fuel assembly that has been designed to increase uranium utilization is the Westinghouse optimized assembly. The assembly is made more reactive by decreasing the fuel rod size while maintaining the same clad thickness. Zircaloy-4 replaces Incone1-718 as the major grid material for extra neutron economy. About $6.5 \%$ savings in uranium consumption is expected (Seif et a1. 1979). A comparison of the present $17 \times 17$ assembly and the Westinghouse optimized assembly is shown in Table 2 .

Increased fuel rod heat flux (for the same core output) and MTC have been analyzed by westinghouse. It is indicated that the heat flux and MTC and other design and regulatory requirements can be satisfied for these design changes (Seif et al. 1979). Discharge compositions of the present $17 \times 17$ assembly versus the Westinghouse optimized assembly were computed with the ORIGEN code (Bel1 1973). Structure compositions as well as fuel compositions were calculated.

The optimized assembly, which has a lighter uranium loading, requires a higher burnup to achieve the same energy extraction which increases the amount 
TABLE 2. Present $17 \times 17$ Versus Optimized Westinghouse Assemblies

\section{Present $17 \times 17$}

Assembly

Relative Moderator Ratio

Fue 1 Rod Diameter (in.)

Clad Thickness (in.)

Fue 1 Pellet Diameter (in.)

Grid Material
0.374

0.0225

0.322

Incone $1-718$
Optimized Assembly

0.360

0.0225

0.309

6 Zircaloy -4

2 Incone $1-718$

(Top and Bottom)

Source: Seif et al. 1979 .

of fission products produced on a per ton basis but the overall fission product yield (MWd/MT) is the same.

CHANGES IN FUEL MANAGEMENT AND PLANT OPERATIONS

Many fuel management and plant operational changes have been considered for improving uranium utilization. Many of these are unattractive because the implementation cost is large compared to potential uranium savings. Some of the changes in this category were reviewed by Combustion Engineering (Decher and Shapiro 1979) and anticipated uranium savings are listed below.

- assembly reinsertion after removing high burnup rods increases reactivity (no benefit)

- radial blanket--triangle corner assemblies (1.5\%)

- axial shim cutback--shorter than fuel rods (0.2\%)

- axial relocation of fue 1 inventory prior to discharge--split and inverted $(0.6 \%)$

- fuel sharing between plants (1.5\%)--12 cycles (yrs)

- increasing moderator temperature $(0.5 \% / 1 \%$ reduction in therma 1 margin). 
Changes in fuel management and plant operation show some promise for PWRs. These include:

- low leakage fuel management

- axial blanket

- power coastdown

- 6-month cycles.

These options are discussed below.

Low Leakage Fuel Management

In conventional 3-batch fuel management, fresh fuel is loaded on the core periphery and older fuel is in a checkerboard pattern in the core interior. This type of fuel management is called an "out-in" strategy. The placement of high enrichment fuel on the core periphery flattens the radial power distribution but increases net radial leakage.

Fue 1 assembly arrangement can be modified by placing once-burned assemblies on the outside and mixing fresh assemblies with once- and twice-burned assemblies in the core interior. Power peaks are controlled with burnable poison rods, which replace about $2 \%$ of the fue 1 rods in the feed batch (Decher and Shapiro 1979 , p. 101).

Low leakage fue 1 management studies show a 2 to $4 \%$ improvement relative to 3-batch out-in fuel management. This savings is potentially larger for a 5batch fue 1 management scheme.

The use of low-leakage fuel management should have little impact on plant effluents. Burnable poison rods, with either boron of gadolinium would contain the activation products generated. Recent improvements in BWR refueling patterns include loading fresh fuel just inside the periphery to flatten power distribution. Movement of fuel from low-power regions at the core periphery to high-power regions of the central core largely avoided, thus reducing the probability of failure from PCI (NASAP 1980, p. 34). This improves the fuel reliability and performance as well as uranium economy. 


\section{Axial Blanket}

The use of a natural uranium reflector has been studied for potential uranium savings. Both the "long fuel rod" case and a "short fuel stack" case (where 6-in. of natural uranium have been added or substituted, respectively) have been investigated by Combustion Engineering (Decher and Shapiro 1979, p. 119). For the long fue 1 rod case, decreased neutron leakage, increased energy extraction, and the addition of an axial blanket yield a net improvement. For the short stack, the benefit comes from reduced energy extraction in core, increased energy extraction in blanket, and reduction in uranium required. This improvement is at the expense of increased linear heat rate and central core burnup, which may lead to more fission gas release (Decher and Shapiro 1979, p. 122). Current BWRs already use natural-uranium axial and radial blankets. A 6-in. blanket region is used at the top and bottom of the fuel column (NASAP 1980, p. 34). Uranium blankets as a fuel savings method causes the same sort of problems as high burnup. The integrity of the fuel under more severe conditions than presentiy demanded will determine the effect on radionuclide releases to the environment.

\section{Power Coastdown}

Coastdown consists of power and secondary pressure reduction, so lower fuel and moderator temperatures provide excess reactivity for extra burnup. A variation on this includes temperature reduction, called "feedwater pressure augmentation" (FWPA), which also increases uranium efficiency.

In a normal coastdown, electrical power is reduced to $80 \%$ in about 25 days. With FWPA, the same power is reached about a week later. FWPA increases energy extraction by about $1.7 \%$ over standard coastdown with 3-batch fue 1 management for first-time extension. The gain is less for equilibrium stretchout. Feedwater pressure augmentation followed by a coastdown to $85 \%$ power can yield $4.1 \%$ uranium savings in an equilibrium cycle; coastdown to $75 \%$ will yield $5.6 \%$ savings at equilbrium (Matzie et al. 1979).

The benefit of coastdown for a 5-batch scheme is $2 / 3$ of that for a 3-batch scheme. The economic optimum coastdown period with FWPA for $20 \mathrm{mi} 11 / \mathrm{kWh}$ 
replacement power cost is about 14 days, or 9 days for $40 \mathrm{mill} / \mathrm{kWh}$ replacement power. Fourteen-day coastdown saves $4.8 \%$ uranium compard with no coastdown (Matzie et al. 1979).

The use of coastdown is not expected to make any adverse changes to plant operational effluents.

Six-Month Cycles

Cycle lengths of 6 months with a 10-batch scheme at 50 GWd/MT burnup would improve uranium utilization by about $9 \%$ relative to the 12 -month 5 -batch case. The use of a 6 -month cycle length depends greatly on the ability to reduce refueling outage time. This option has been considered as a nonretrofitable option by NASAP (NASAP 1980, p. 30). Short cycles would increase the fuel handling. Increased handling appears to be the only reason to expect a change in radionuclide releases if short cycles become standard practice.

\section{BWR Spectral Shift}

In spectral shift by void control, the reactor is operated with low coolant recirculation (high void) during most of the cycle to harden the spectrum and increase conversion ratio. At end of cycle, the reactor would be operated with maximum coolant recirculation (low void). The potential uranium savings are from 4 to $8 \%$. Existing plants may be able to use spectral shift to some degree, depending on the particular plant design. To determine acceptable flow ranges at full power operation for retrofit and to obtain NRC acceptance would require experimental examination of BWR transient heat flux characteristics, flow induced vibration measurements, steam separator performance measurements, and other tests involving primary system components (NASAP 1980, p. 38).

At the end of core life in any LWR, a greater proportion of energy is generated with plutonium than is at the beginning of core life where there is a substantial amount of fresh fuel. This difference is emphasized with BWR spectral shift where even a larger portion of plutonium fission can occur as the spectrum is softened towards the end of the operation cycle.

Fission yields at mass 109 (Ru, Rh 109, for example) and at mass 160 are about 50 times greater for plutonium fission than for uranium fissions. Around 
mass 109 , the plutonium fission yields are less than $1 \%$; around 160 , less than $0.01 \%$. At the middle of the fission yield curve, about mass 120 , there is a factor of three difference in plutonium and uranium yields. The yields in the middle region are in the 0.01 to $1.0 \%$ range.

Yields of some fission products of interest in reactor operations such as the volatile fission products are different in uranium versus plutonium fissions. The fission of ${ }^{239} \mathrm{Pu}$ will yield $30 \%$ more fission products of mass 131 (overall 3\% yield), 5\% more mass 133 (7\% yield), and about $1 \%$ less mass 134 . The plutonium fission yield of mass 135 is $14 \%$ greater, and mass $137,7 \%$ greater for plutonium than for uranium. The 131 and 133 mass decay chains have the most impact because they contain the problem isotopes ${ }^{13 I_{I}}$ and ${ }^{133} \mathrm{I}$.

Calculations with LEOPARD (Barry 1963) show that at the end of fuel life, over half the power generated is from plutonium fissions, even without spectral shift. The overall power production, averaged over the core life is about $62 \%$ from uranium fissions, with most of the remainder from ${ }^{239} \mathrm{Pu}$ fissions. Spectral shift can increase the production of plutonium by $20 \%$ to further change the fission yields at end of core life. Since these changes are averaged in with the other batches of fuel in the core and the short half-life isotopes approach a steady-state value, the resulting changes are small.

\section{Thorium Corner Rods in BWR Assemblies}

The use of thorium in BWRs has been investigated by the General Electric Company. Substitution of $\mathrm{ThO}_{2}$ rods for $\mathrm{UO}_{2}$ in the corners of fuel bundles improved reactor dynamic and control characteristics (Williamson 1978, pp. 1-5). The four corner rods can be withdrawn and used directly in the next generation of fuel without reprocessing, however, bundle reconstitution is required.

The thorium corner rod design requires about $1 \%$ more uranium and $4 \%$ more separative work than the $\mathrm{UO}_{2}$ stowaway cycle (Williamson 1978, pp. 6-26), assuming the thorium rods are not reinserted after discharge. Uranium recycle is necessary to improve resource utilization with thorium in a BWR relative to the $\mathrm{UO}_{2}$ stowaway cycle. The once-through BWR thorium cycle may use $\mathrm{ThO}_{2} /$ $233 \mathrm{U}$ rods reinserted in blanket bundles. A long-lifetime thorium radial blanket may reduce uranium requirement by $4 \%$ (Crowther et al. 1979). 
Discharge composition of alternative fuels are calculated in an earlier ECT task (Nolan et al. 1979). Wastes from reprocessing the ${ }^{233} \mathrm{U}$-containing fuel tended to result in higher hazard indices and larger doses than other fuels.

Thorium-bred $233 \mathrm{U}$ in reactors would have some effect on fission products generated. The major differences in fission yields occur at masses 80-90, 95105, and 120-130. The differences in these yields are predominantly less than a factor of two. In the mass range of 85 through $88,{ }^{233} \mathrm{U}$ fission yields 50 to $70 \%$ more fission fragments than ${ }^{235} \mathrm{U}$. (This is in the 1 to $6 \%$ yield part of the curve.) In the mass 131-137 ( $\mathrm{I}, \mathrm{Xe}, \mathrm{Cs}$ ) range of the fission product distribution curve, the ${ }^{233} U$ and ${ }^{235} U$ yields are within $30 \%$ of each other. (Each mass number in this range is 3 to $7 \%$ yield.)

The effects of these changes are minimized because thorium constitutes on ly $5.8 \%$ of the heavy metal loading of the core. The percentage of ${ }^{233} \mathrm{U}$ will be much smaller, since it is bred from the small amount of thorium in the reactor. Therefore, the use of thorium corner rods would have a small effect on reactor effluents. 


\section{REFERENCES}

Barry, R. F. 1963. "LEOPARD - A Spectrum-Dependent Non-Spatial Depletion Code for the IBM-7094." WCAP-3269-26.

Be11, M. J. 1973. ORIGEN: The ORNL Isotope Generation and Depletion Code. ORNL-4628, Oak Ridge National Laboratory, Oak Ridge, Tennessee.

Bobe, P. E. 1976. Fuel Performance of Licensed Nuclear Power Plants Through 1974. NUREG-0032, Office of Management Information and Program Contro1, Performance Evaluation Branch, Nuclear Regulatory Commission, Washington, D.C.

Bradley, E. R., M. E. Cunningham, C. R. Hann, D. D. Lanning, R. E. Williford. 1979. "Burnup-Dependent Fission Gas Release." In Transactions of the ANS Winter Meeting, San Francisco, California, November 11-15, 1979, 33:272273.

Decher, U. and N. L. Shapiro. 1979. Improvements in Once-Through PWR Fue 1 Cycles. CEND-376, Interim Progress Report for fiscal year 1978. Prepared for U.S. Department of Energy by Combustion Engineering Power Systems.

Heeb, C. M., R. L. Aaberg, B. M. Cole, R. L. Engel, W. E. Kennedy, Jr., and M. A. Lewallen. 1980. A Survey of LWR Environmental Control Technology Performance and Cost. PNL-2287, Pacific Northwest Laboratory, Richland, Washington.

Keepin, R. G. 1965. Physics of Nuclear Kinetics. Addison Wesley Publishing Co., Inc.

Matzie, R. A., D. C. Leung, Y. Liu, and R. W. Beekman. 1979. "The Benefits of Cycle Stretchout in PWR Extended Burnup Fuel Cycles." TIS-6469, paper presented at the ANS Winter Meeting, November 11-15, 1979, San Francisco, California.

Nolan, A. M., M. A. Lewallen, and G. W. McNair. 1979. Environmental Control Aspects for Fabrication, Reprocessing, and Waste Disposal of ATternative LWR and LMFBR Fuels. PNL-3129, Pacific Northwest Laboratory, Richland, Washington.

Ranjan, G. V. and E. Smith. 1975. "Fracture of Zircaloy Cladding as a Consequence of Power Increases in Water Reactor Fuel Rods." In Structural Mechanics in Reactor Tecnology, Vol. C, EPRI LWR Fue 1 Rod Performance Program.

Roesmer, J. and M. W. Rootham. 1978. "Estimation of Activity Inventories in Primary Circuits of PWRs." In Water Chemistry of Nuclear Reactor Systems, proceedings of an International Conference organized by the British Nuclear Energy Society, pp. 187-193, British Nuclear Energy Society, London. 
Schneider, K. J. and T. J. Kabele. 1979. Descriptions of Reference LWR Facilities for Analys is of Nuclear Fuel Cycles Appendices. PNL-2286 APP, Pac ific Northwest Laboratory, Richland, Washington.

Seif, R. E., R. G. McGrath, D. A. Hollein. 1979. "Optimized Nuclear Fuel Design from Changing Fuel Economics." Paper presented at the American Power Conference, April 23-25, 1979, Chicago, Illinois.

Solomon, Y. 1978. "An Overview of Water Chemistry for Pressurized Water Nuc lear Reactors." In Water Chemistry of Nuclear Reactor Systems, proceedings of an International Conference organized by the British Nuclear Energy Soc iety, pp. 101-112, British Nuclear Energy Society, London.

Trevorrow, L. E., B. J. Kullen, R. L. Jarry, and M. J. Steindler. 1974. Tritium and Noble-Gas Fission Products in the Nuclear Fuel Cycle, I. Reactors. ANL-8102, Argonne National Laboratory, Argonne, I11 ino is.

U.S. Department of Energy. 1980. Nuclear Proliferation and Civilian Nuclear Power. Report of the Nonproliferation Alternative Systems Assessment Program (NASAP), Volume IX: Reactor and Fuel Cycle Description. Office of Nuclear Energy Programs, Washington, D.C.

Williamson, H. E. 1978. Assessment of Utilization of Thorium in BWRs. Prepared for Oak Ridge National Laboratory by General Electric Company, Nationa 1 Technical Information Service, Springfield, Virginia. 


\section{DISTRIBUTION}

No. of

Copies

OFFS ITE

A. A. Churm

DOE Chicago Patent Group

9800 South Cass Avenue

Argonne, IL 60439

R. W. Ramsey

U.S. Department of Energy Environmental and Safety

Engineering Division

Washington, DC 20545

W. E. Mott

U.S. Department of Energy Environmental and Safety

Engineering Division Washington, DC 20545

J. Counts

U.S. Department of Energy

Environmental and Safety

Engineering Division

Washington, DC 20545

27 DOE Technical Information Center

\section{ONSITE}

DOE Richland Operations

H. E. Ransom
No. of

Copies

31 Pacific Northwest Laboratory

R. L. Aaberg (5)

W. J. Bair

A. Brandstetter

D. B. Cear lock

R. M. Fle ischman

A. J. Haverfield

C. M. Heeb

D. L. Hesse 1

J. H. Jarrett

H. V. Larson

R. C. Liikala

R. W. McKee

D. E. Newman

J. M. Nielsen

A. M. Nolan

T. B. Powers

R. J. Serne

B. E. Vaughn

E. C. Watson

L. D. Williams

Technical Information (5)

Publishing Coordination $\mathrm{KE}(2)$ 
, 